УДК 338.1: 336.6

$10.17213 / 2075-2067-2021-4-124-132$

\title{
КОРРЕЛЯЦИОННО-РЕГРЕССИОННЫЙ АНАЛИЗ ИСЛАМСКИХ ФИНАНСОВ
}

\section{(C) 2021 г. И. Н. Ииемгулов}

\author{
Баикирский государственный университет, г. Уфа, Россия
}

Цель исследования: выявить закономерности и взаимосвязи в исламских финансах.

Методы исследования: анализ и синтез, системный подход, а также методы корреляичионо-регрессионного анализа.

Результаты исследования. Предложен методический подход к применению инструментов коррелячионно-регрессионного анализа в моделировании исламских финансов. В качестве результативного при проведении коррелящионно-регрессионного анализа и построении математических моделей предлагается использовать объем финансирования инвестиций исламской финансовой организаџией. В числе зависимых переменных и факторов, влияющих на объем финансирования инвестиций исламской финансовой организацией, предлагается использовать переменные, характеризующие капитал (такие показатели, как оплаченный капитал финансовой исламской организации, суммарные активы, суммарные обязательства, собственный капитал финансовой исламской организаџии), а также показатели дохода и прибыли финансовой исламской организаџии (такие показатели, как общиий доход (выручка) и чистая прибыль финансовой исламской организащии). Апробащия предложенного подхода осуществлена на примере крупнейшей исламской финансовой организации - Исламского банка развития (Islamic Development Bank). Разработаны многофакторные экономико-статистические модели зависимости объема финансирования инвестиций от ряда факторов. По результатам расчетов выявлена сильная корреляционная связь между объемом инвестиций исламской финансовой организации и величинами оплаченного капитала, суммарных обязательств, собственного капитала, общего дохода и чистой прибыли. Предсказанные значения расположены максимально близко к остаточным значениям, что свидетельствует о том, что полученное уравнение регрессии имеет высокую степень точности.

Перспективы исследования: результаты исследования могут быть использованы для выявления значимых факторов развития исламских финансов в Российской Федераџии.

Ключевые слова: исламские финансы; Исламский банк развития; инвестиции исламской финансовой организаџии; активы исламской финансовой организаџии; доход исламской финансовой организации; чистая прибыль исламской финансовой организации; корреляционно-регрессионный анализ; коэффищиент корреляции.

\section{CORRELATION AND REGRESSION ANALYSIS OF ISLAMIC FINANCE}

\section{(C) 2021 I. N. Ishemgulov}

\section{Bashkir State University, Ufa, Russia}

Purpose of the study: to identify patterns and relationships in Islamic finance.

Methods of the study: analysis and synthesis, systematic approach, as well as methods of correlation and regression analysis. 
The results of the study. A methodological approach to the use of correlation-regression analysis tools in the modeling of Islamic finance has been proposed. It is proposed to use the volume of investment financing by an Islamic financial organization as effective in carrying out the correlation-regression analysis and constructing mathematical models. Among the dependent variables and factors affecting the volume of investment financing by an Islamic financial organization, it is proposed to use variables characterizing capital (such indicators as paidin capital of a financial Islamic organization, total assets, total liabilities, equity of a financial Islamic organization), as well as indicators of income and profit a financial Islamic organization (indicators such as total income (revenue) and net profit of a financial Islamic organization). Approbation of the proposed approach was carried out on the example of the largest Islamic financial organization - the Islamic Development Bank. Multivariate economic and statistical models have been developed for the dependence of the volume of investment financing on a number of factors. According to the results of calculations, a strong correlation was revealed between the volume of investments of an Islamic financial organization and the values of paid-in capital, total liabilities, equity capital, total income and net profit. The predicted values are located as close as possible to the residual values, which indicates that the resulting regression equation has a high degree of accuracy.

The prospect of the study: the research results can be used to identify significant factors in the development of Islamic finance in the Russian Federation.

Key words: islamic finance; Islamic Development Bank; investments of an Islamic financial organization; assets of an Islamic financial organization; income of an Islamic financial organization; net profit of an Islamic financial organization; correlation and regression analysis; correlation coefficient.

Введение. Исламские финансы, под которыми мы в рамках данного исследования понимаем совокупность финансовых учреждений и инструментов, соответствующих нормам исламского права - шариата, занимают важное место в мировых финансах. В состав исламских финансов относятся не только исламские банки, но и фонды, лизинговые и страховые компании, а также микрофинансовые организации. Поиск оптимальных параметров, характеризующих исламские финансы, определяет стратегическую направленность развития исламских финансов.

Использование инструментов корреляционно-регрессионного анализа помогает выявить закономерности, что позволит эффективно управлять исламскими финансами с научной точки зрения.

Корреляционный анализ состоит в определении степени (тесноты) связи между случайными величинами, регрессионный - в исследовании формы связи между ними. Корреляционно-регрессионный анализ как общее понятие включает в себя измерение тесноты, определение направления связи и установление аналитического выражения связи.

Ключевым показателем деятельности исламских финансовых организаций является объем инвестиций, который осуществляют исламские финансовые организации.

Целью корреляционно-регрессионного анализа исламских финансов является выяснение связи между рассматриваемыми признаками. Если такая связь существует, вычисляется мера зависимости и находится математическое уравнение, более или менее ее отражающее.

Методика исследования. В рамках данного исследования предлагается методический подход к применению инструментов корреляционно-регрессионного анализа для моделирования исламских финансов.

В качестве результирующего показателя (У) предлагается использовать показатель объема финансирования инвестиций исламской финансовой организацией. 
Предлагаемые зависимые показатели для модели:

- $\mathrm{X}_{1}$ - оплаченный капитал финансовой исламской организации;

- $\mathrm{X}_{2}$ - суммарные активы финансовой исламской организации;

- $\mathrm{X}_{3}$ - суммарные обязательства финансовой исламской организации;

- $\mathrm{X}_{4}$ - собственный капитал финансовой исламской организации;

- $\mathrm{X}_{5}$ - общий доход (выручка) финансовой исламской организации;

- $\mathrm{X}_{6}$ - чистая прибыль финансовой исламской организации.

Этапы построения корреляционно-регрессионной модели следующие. $[6,7]$.

Этап 1. Формирование массива данных

Этап 2. Проведение корреляционного анализа, построение корреляционной матрицы, отбор факторов в модель с использованием инструмента «Корреляция» в пакете «Анализ данных» MS Excel.

Инструмент «Корреляция» определяет коэффициент корреляции между двумя множествами данных (интервалами ячеек массив 1 и массив 2). Основная задача корреляционного анализа заключается в выявлении взаимосвязи между случайными переменными путем точечной и интервальной оценки парных (частных) коэффициентов корреляции и детерминации. Кроме того, с помощью корреляционного анализа решаются следующие задачи: отбор факторов, оказывающих наиболее существенное влияние на результативный признак, на основании измерения степени связи между ними; обнаружение ранее неизвестных причинных связей.

Этап 3. Проведение регрессионного анализа, построение уравнения регрессии, обоснование полученной зависимости с использованием инструмента «Регрессия» в пакете «Анализ данных» MS Excel [8-10].

С помощью этого инструмента выполняется линейный регрессионный анализ. Регрессия подбирает график для набора наблюдений с помощью метода наименьших квадратов. Регрессия используется в широком диапазоне приложений для анализа воздействия на отдельную зависимую переменную факторов, значений одной или более независимых переменных.
Регрессионный анализ предназначен для исследования зависимости исследуемой переменной от различных факторов и отображения их взаимосвязи в виде регрессионной модели. Группа итоговых выходных таблиц (ВЫВОД ИТОГОВ) будет включать следующие таблицы: Регрессионная статистика: Множественный R, R-квадрат, Нормированный R-квадрат, Стандартная ошибка (оценка стандартного отклонения выборки), Наблюдения (счет); Дисперсионный анализ (Регрессия, Остаток, Итого (столбцы df, SS, MS, F - значение критерия Фишера для выборки), Значимость $F$ (вероятность ошибочного отклонения нулевой гипотезы для F)), Коэффициенты (коэффициенты регрессии для определения наличия взаимосвязи между массивами зависимой и независимыми переменными), Стандартная ошибка, t-статистика (критерий Стьюдента), Р-Значение, Нижние $95 \%$, Верхние $95 \%$, Нижние $95.000 \%$, Верхние $95.000 \%$ (границы интервальных оценок для математического ожидания и дисперсии).

Качество уравнения регрессии оценивается с помощью коэффициента детерминации (R-квадрат). Оценка значимости уравнения регрессии в целом дается с помощью $F$-критерия Фишера. Если $F_{\text {набл }}>F_{\text {табл }}$, уравнение регрессии считается статистически значимым, в противном случае - статистически незначимым. Проверка значимости отдельных коэффициентов регрессии осуществляется с помощью $t$-критерия Стьюдента. Расчетные значения сравниваются с табличными, определенными при $n-2$ степенях свободы и соответствующем уровне значимости $a$. Кроме того, использование инструмента «Регрессия» позволяет получить графическое изображение остатков, подбора, нормальной вероятности.

Апробация методики. В настоящее время на рынке исламских финансов доминирующие позиции распределены между семью странами: Ираном (30\% доля мирового рынка исламских финансов), Саудовской Аравией (24\%), Малайзией $(11 \%)$, Объединенными Арабскими Эмиратами $(10 \%)$, Катаром (5\%) и Бахрейном (4\%). В той или иной форме совокупные активы исламских финансов превышают 2 трлл. долл. США [1]. 
Апробация предложенного методического подхода проведена на примере Исламского банка развития (IsDB - Islamic Development Bank) [4]. Это международная финансовая организация, которая ориентирована на исламское финансирование. Исламский банк развития был основан в 1974 г. и в настоящее время является мировым лидером в области исламских финансов, предоставляя долгосрочные устойчивые и этичные структуры финансирования для поддержки инвестиций в свои проекты. За последние два десятилетия банк получил рейтинг ААА и стал крупнейшим глобальным эмитентом сукук (эквивалент облигаций). В настоящее время в состав Исламского банка развития входят 57 стран из Ближнего Востока, Африки, Азиатско-Тихоокеанского региона, Южной Азии, Европы и Южной Америки. Основным условием членства является то, что потенциальная страна-член должна быть членом Организации исламского сотрудничества (OIC). Все финансовые операции осуществляются в соответствии с исламским правом (шариатом). Проектное финансирование, кредиты и техническая помощь Исламского банка развития направлены на развитие сельского хозяйства, базовой инфраструктуры и промышленных секторов, образования, учреждений здравоохранения и других учреждений социального сектора, а также инвестиции в развитие финансовых институтов.

В таблице 1 представлены основные акционеры Исламского банка развития по состоянию на 01.01.2021 г.

По состоянию на 01.01.2020 г.: общие активы банка - 32,6 млрд. руб., подписанный акционерный капитал (собственный капитал) -

Таблица 1

Основные акционеры Исламского банка развития по состоянию на 01.01.2021 г. [4]

\begin{tabular}{|c|l|c|c|}
\hline Место & \multicolumn{1}{|c|}{ Страна } & Сумма капитала, млрд. долл. США & \% от общего капитала \\
\hline 1 & Саудовская Аравия & 11,9 & 23,5 \\
\hline 2 & Ливия & 4,8 & 9,43 \\
\hline 3 & Иран & 4,2 & 8,25 \\
\hline 4 & Нигерия & 3,9 & 7,66 \\
\hline 5 & ОАЭ & 3,8 & 7,51 \\
\hline 6 & Катар & 3,6 & 7,18 \\
\hline 7 & Египет & 3,6 & 7,07 \\
\hline 8 & Кувейт & 3,5 & 6,92 \\
\hline 9 & Турция & 3,3 & 6,45 \\
\hline 10 & Алжир & 1,3 & 2,54 \\
\hline
\end{tabular}

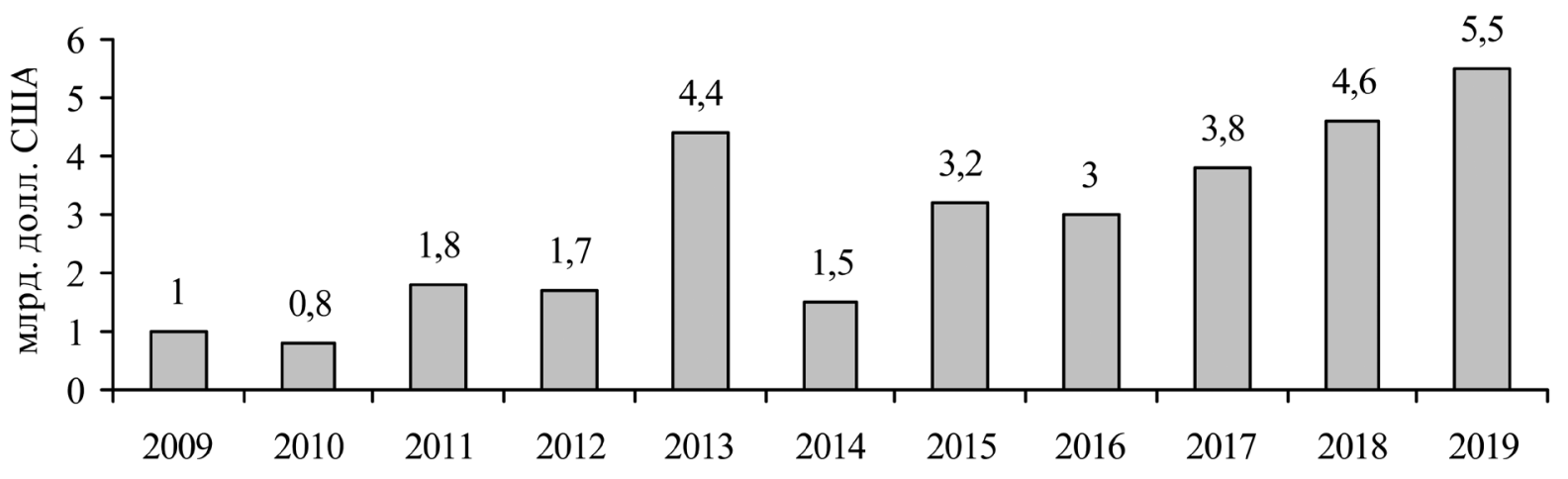

Рис. 1. Динамика объемов финансирования инвестиций Исламским банком развития (составлено автором по данным [9]) 
69,5 млрд. руб., оплаченный капитал - 8 млрд. долл. США, отношение долга и собственного капитала (Debt/Equity) — 156,2\%, отношение активов к общей сумме обязательств (Assets/ Total Liabilities) — 162,5\%, отношение ликвидных активов к общей сумме обязательств (Liquid Assets/Total Liabilities) — 50,6\% [9].

На рис. 1. представлена динамика объемов финансирования инвестиций Исламским банком развития за 2009-2019 гг.

Выявим зависимости между объемом финансирования инвестиций и показателями деятельности Исламского банка развития.

В таблице 2 представлены первичные значения показателей Исламского банка развития, на основании которых проведены дальнейшие расчеты.
Коэффициенты парных корреляций, отражающих взаимосвязи между показателями, приведены в таблице 3.

Как видно из полученной корреляционной матрицы, наиболее тесные корреляционные связи наблюдаются между $\mathrm{X}_{1}$ и $\mathrm{Y}, \mathrm{X}_{2}$ и $\mathrm{Y}$, $\mathrm{X}_{3}$ и $\mathrm{Y}, \mathrm{X}_{4}$ и $\mathrm{Y}, \mathrm{X}_{5}$ и $\mathrm{Y} . \mathrm{B}$ то же время между рассматриваемыми факторными признаками наблюдается мультиколлинеарность, что значительно ухудшит качество уравнения регрессии, поэтому фактор $\mathrm{X}_{2}$ исключим для получения достоверной оценки по регрессионной модели.

Выведем регрессионное уравнение, отражающее зависимость объема финансирования инвестиций $(\mathrm{Y})$ от оплаченного капитала $\left(\mathrm{X}_{1}\right)$, суммарных обязательств $\left(\mathrm{X}_{3}\right)$, собственного

Таблица 2

Показатели Исламского банка развития для проведения корреляционного регрессионного анализа, млрд. долл. США [9, 10]

\begin{tabular}{|l|c|c|c|c|c|c|c|}
\hline \multicolumn{1}{|c|}{ Показатель } & Обозначение & 2014 & 2015 & 2016 & 2017 & 2018 & 2019 \\
\hline $\begin{array}{l}\text { Объем } \\
\text { финансирования } \\
\text { инвестиций }\end{array}$ & $\mathrm{y}$ & 1,5 & 3,2 & 3 & 3,8 & 4,6 & 5,5 \\
\hline Оплаченный капитал & $\mathrm{X}_{1}$ & 6,7 & 6,8 & 7,1 & 7,4 & 7,7 & 8 \\
\hline Суммарные активы & $\mathrm{X}_{2}$ & 22,388 & 22,26 & 25,094 & 27,209 & 30,488 & 32,599 \\
\hline $\begin{array}{l}\text { Суммарные } \\
\text { обязательства }\end{array}$ & $\mathrm{X}_{3}$ & 10,922 & 11,406 & 13,575 & 15,434 & 18,402 & 20,063 \\
\hline Собственный капитал & $\mathrm{X}_{4}$ & 11,467 & 10,855 & 11,519 & 11,777 & 12,086 & 12,536 \\
\hline Общий доход & $\mathrm{X}_{5}$ & 0,529 & 0,556 & 0,952 & 0,796 & 0,744 & 0,859 \\
\hline Чистая прибыль & $\mathrm{X}_{6}$ & 0,245 & 0,218 & 0,425 & 0,272 & 0,116 & 0,194 \\
\hline
\end{tabular}

Таблица 3

Значения коэффициентов парных корреляций при использовании инструмента «Корреляция» (рассчитано автором)

\begin{tabular}{|l|r|r|r|r|r|r|r|}
\hline & \multicolumn{1}{|c|}{$\mathrm{y}$} & \multicolumn{1}{c|}{$\mathrm{X}_{1}$} & \multicolumn{1}{c|}{$\mathrm{X}_{2}$} & \multicolumn{1}{c|}{$\mathrm{X}_{3}$} & \multicolumn{1}{c|}{$\mathrm{X}_{4}$} & $\mathrm{X}_{5}$ & $\mathrm{X}_{6}$ \\
\hline $\mathrm{y}$ & 1 & & & & & & \\
\hline $\mathrm{X}_{1}$ & 0,941 & 1 & & & & & \\
\hline $\mathrm{X}_{2}$ & 0,914 & 0,996 & 1 & & & & \\
\hline $\mathrm{X}_{3}$ & 0,932 & 0,997 & 0,999 & 1 & & & \\
\hline $\mathrm{X}_{4}$ & 0,735 & 0,915 & 0,939 & 0,920 & 1 & & \\
\hline $\mathrm{X}_{5}$ & 0,543 & 0,622 & 0,598 & 0,597 & 0,563 & & \\
\hline $\mathrm{X}_{6}$ & $-0,44544$ & $-0,40633$ & $-0,43157$ & $-0,44146$ & $-0,33776$ & 0,440 & \\
\hline
\end{tabular}


капитала $\left(\mathrm{X}_{4}\right)$, общего дохода $\left(\mathrm{X}_{5}\right)$. Результаты расчетов приведены в таблицах 4, 5 и 6.

Полученная регрессионная зависимость находится в области достаточной аппроксимации (R-квадрат 0,94 > 0,8). Выбранные факторы существенно влияют на величину объема финансирования инвестиций.

Расчетное значение $F$-критерия Фишера 4 попадает в критический интервал $(0,36$; $+\infty)$. Это свидетельствует о том, что коэффи- циент детерминации найденной регрессионной зависимости является значимым.

Сравнивая попарно t-статистики и р-значения для всех коэффициентов, оставим те, где значения t-статистики больше р-значения. Эти факторы значимы. Таким образом, исключили из уравнения $\mathrm{X}_{3}$ и $\mathrm{X}_{6}$. График подбора по $\mathrm{X}_{1}$ и $\mathrm{X}_{5}$ представлен на рисунках 2 и 3.

Поскольку предсказанные значения расположены максимально близко к остаточным

\section{Результаты регрессионной статистики при использовании инструмента «Регрессия» MS Excel (рассчитано автором)}

Таблица 4

\begin{tabular}{|l|c|}
\hline \multicolumn{1}{|c|}{ Регрессионная статистика } & Значение параметра \\
\hline Множественный R & 0,97 \\
\hline R-квадрат & 0,94 \\
\hline Нормированный R-квадрат & 0,71 \\
\hline Стандартная ошибка & 0,75 \\
\hline Наблюдения & 6 \\
\hline
\end{tabular}

Таблица 5

Результаты дисперсионного анализа при использовании инструмента «Регрессия» (рассчитано автором)

\begin{tabular}{|l|c|c|c|c|c|}
\hline \multicolumn{2}{|l|}{ Дисперсионный анализ } & & & \\
\hline & $d f$ & $S S$ & $M S$ & $F$ & Значимость $F$ \\
\hline Регрессия & 4 & 9,02 & 2,25 & 4 & 0,36 \\
\hline Остаток & 1 & 0,56 & 0,56 & & \\
\hline Итого & 5 & 9,58 & & & \\
\hline
\end{tabular}

Результаты использования инструмента «Регрессия» MS Excel

\begin{tabular}{|c|c|c|c|c|c|c|c|c|}
\hline & 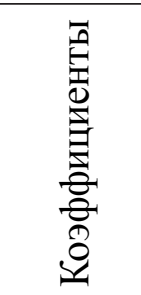 & 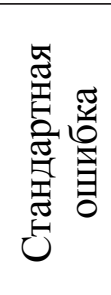 & 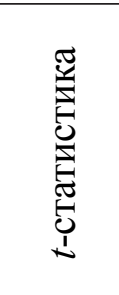 & 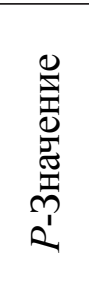 & o̊ & 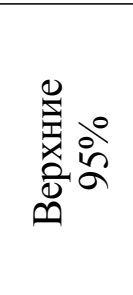 & 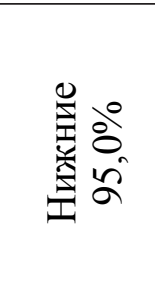 & 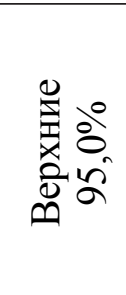 \\
\hline Y-пересечение & $-57,85$ & 56,9 & $-1,02$ & 0,49 & $-780,8$ & 665,11 & $-780,81$ & 665,11 \\
\hline $\mathrm{X}_{1}$ & 11,5 & 11,3 & 1,02 & 0,49 & $-132,0$ & 155,03 & $-132,02$ & 155,03 \\
\hline $\mathrm{X}_{3}$ & $-1,69$ & 1,87 & $-0,91$ & 0,53 & $-25,42$ & 22,03 & $-25,42$ & 22,029 \\
\hline $\mathrm{X}_{5}$ & 9,56 & 12,89 & 0,74 & 0,59 & $-1542,2$ & 173,31 & $-154,19$ & 173,31 \\
\hline $\mathrm{X}_{6}$ & $-16,57$ & 19,65 & $-0,84$ & 0,55 & $-266,3$ & 233,15 & $-266,31$ & 233,15 \\
\hline
\end{tabular}


значениям, то мы можем сделать вывод о том, что полученное уравнение регрессии имеет высокую степень точности $[5,6]$.

Полученные значения коэффициентов регрессии позволяют записать уравнение регрессии в следующем виде:

$$
\mathrm{Y}=11,5 \times \mathrm{X}_{1}+9,56 \times \mathrm{X}_{5} \text {, }
$$

где Y - объем финансирования инвестиций, млн. долл.; $\mathrm{X}_{1}$ - величина оплаченного капитала, млн. долл.; $\mathrm{X}_{5}$ - величина общего дохода, млн. долл.

Полученное уравнение регрессии ставит объем финансирования инвестиций в прямую зависимость от величины оплаченного капитала и величины общего дохода. Полученное уравнение регрессии читается следующим образом: увеличение величины оплаченного капитала приводит к росту объема финансирования инвестиций на 11,5 млрд. долл., а рост общего дохода Исламского банка приводит к росту объема финансирования инвестиций на 9,56 млрд. долл.

\section{Выводы}

1. Для выявления факторов, влияющих на потенциальные финансовые возможности исламской организации по финансированию инвестиций, предлагается использование инструментов корреляционно-регрессионного анализа, в том числе расчет и анализ коэффициен-

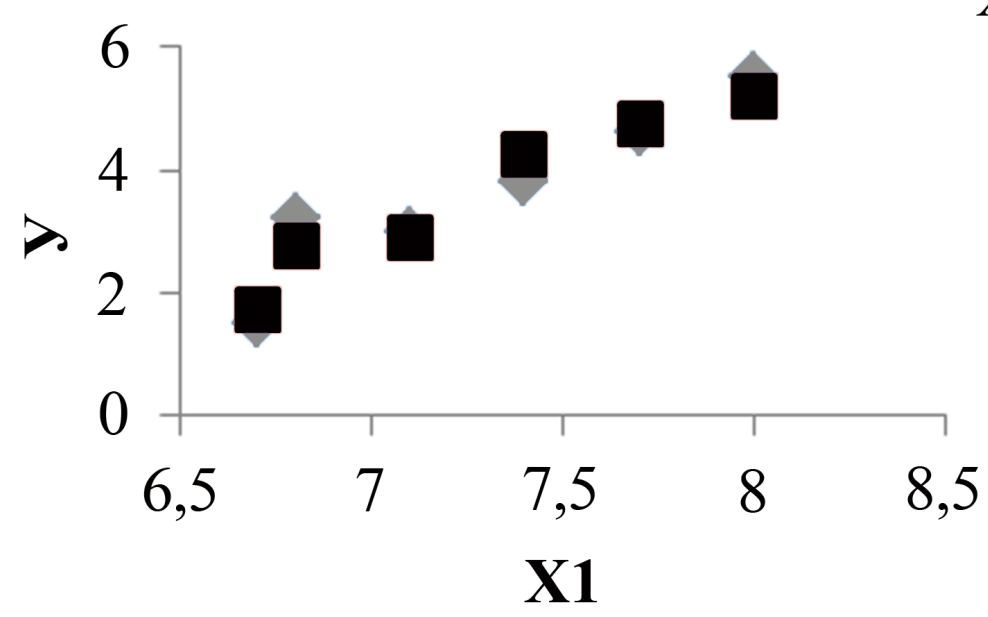

Х1 График подбора

Рис. 2. График подбора объема финансирования инвестиций (У) по оплаченному капиталу $\mathrm{X}_{1}$

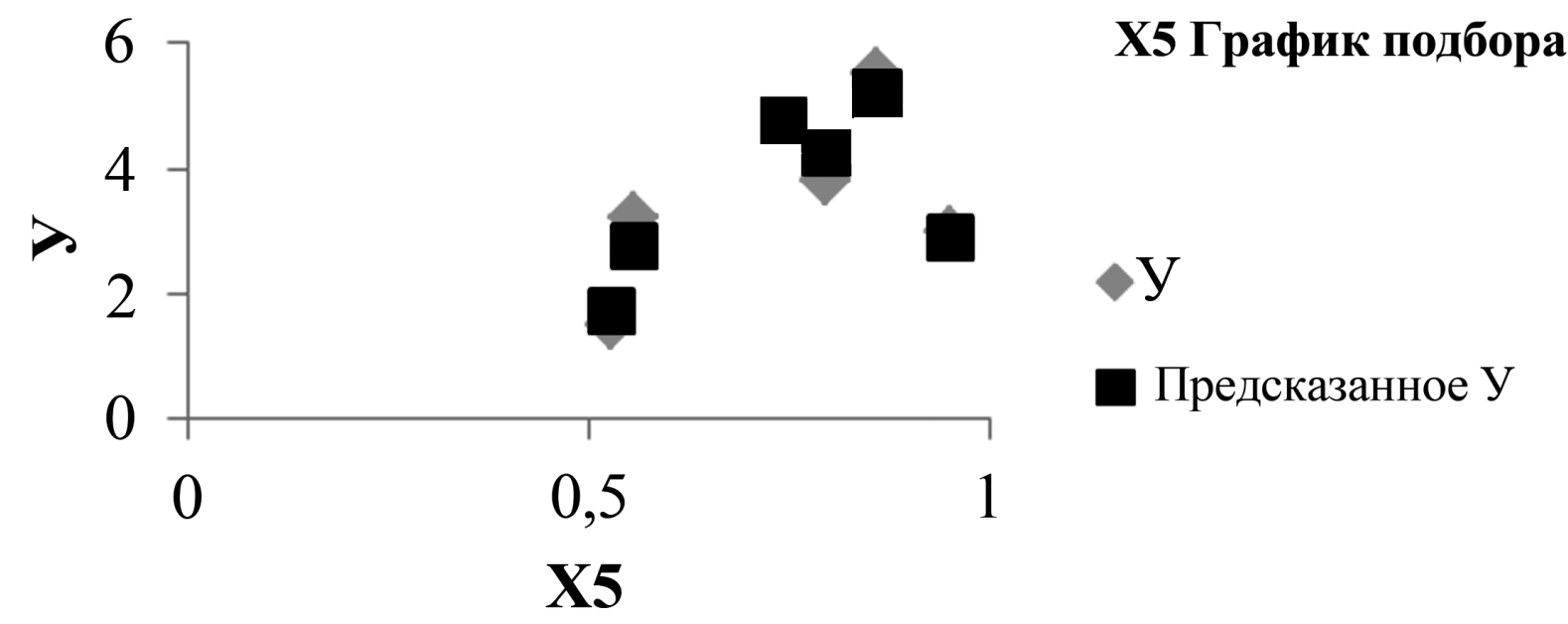

Рис. 3. График подбора объема финансирования инвестиций $(\mathrm{Y})$ по общему доходу $\left(\mathrm{X}_{5}\right)$ 
тов корреляции, построение и оценка параметров многофакторных регрессионных моделей, расчет и анализ коэффициентов эластичности.

2. По результатам апробации предложенного подхода на примере Исламского банка развития выявлена сильная корреляционная связь между объемом инвестиций исламской финансовой организации и величинами оплаченного капитала, суммарных обязательств, собственного капитала, общего дохода и чистой прибыли.

3. Установлено, что предсказанные значения показателей объема финансирования инвестиций по оплаченному капиталу и по общему доходу расположены максимально близко к остаточным значениям, что свидетельствует о том, что полученное уравнение регрессии имеет высокую степень точности.

\section{Литература}

1. Нагимова А. 3. Исламские финансы в странах СНГ: монография / А. 3. Нагимова. - Москва: ИНФРА-М, 2021. - 219 с.

2. Низамова Г.3., Гайфуллина М.М. Корреляционно-регрессионный анализ эффективности использования инвестиционных ресурсов нефтяной компании // Вестник УГНТУ. T. 1. - №35. - C. 15-23.

3. Низамова Г.З., Гайфуллина М.М., Бакулина Д.С. Оценка влияния факторов на эффективность инвестиционной деятельности нефтяной компании // Евразийский юридический журнал. - 2018. - №10. - С. 460-461.

4. Официальный сайт Исламского банка развития Islamic Development Bank [Электронный ресурс]. - Режим доступа: https:// www.isdb.org/isdb-member-countries.

5. Amendola A., Giordano F., Parrella M.L., Restaino M. Variable selection in high-dimensional regression: a nonparametric procedure for business failure prediction // Applied Stochastic Models in Business and Industry. - 2017. №33 (4). - Pp. 355-368. - DOI: https://doi. org/10.1002/asmb.2240.

6. Gajfullina M.M., Nizamova G.Z., Musina D. R., Alexandrova O.A. Formation of strategy of effective management of fixed production assets of oil company // Advances in Economics, Business and Management Research. 2017. - Vol. 38. - Pp. 185-190. - DOI: https://doi.org/10.2991/ttiess-17.2017.32.
7. Gayfullina M. M, Nizamova G.Z., Musina D.R., Gareeva Z.A., Tumanova A. U. An integrated approach to assessing the effectiveness of investment projects for the construction of industrial facilities under uncertainty // IOP Conference Series: Earth and Environmental Science, Vol. 751. International Baikal Investment and Construction Forum «Spatial Restructuring of territories» (4 December 2020, Irkutsk, Russian Federation). - Pp. 1-8. - DOI:10.1088/17551315/751/1/012074.

8. Lee C.F., Chen H. Y., Lee J. Econometric Approach to Financial Analysis, Planning, and Forecasting / In: Financial Econometrics, Mathematics and Statistics. - Springer, New York, NY, 2019. - DOI: https://doi. org/10.1007/978-1-4939-9429-8_5.

9. IsDB Investor Presentation (March 2021) [Электронный ресурс]. - Режим доступа: https://www.isdb.org/pub/generalpublications/2021/isdb-investor-presentationmarch-2021.

10. IsDB Sustainable Investor Presentation (November 2019) [Электронный ресурс]. Режим доступа: https://www.isdb.org/pub/reports/2019/isdb-sustainable-investor-presentation-november-2019.

\section{References}

1. Nagimova A.Z. Islamskie finansy $\mathrm{v}$ stranah SNG: monografija [Islamic finance in the CIS countries: a monograph] / A.Z. Nagimova. - Moscow: INFRA-M, 2021. - 219 p.

2. Nizamova G.Z., Gajfullina M.M. Korreljacionno-regressionnyj analiz jeffektivnosti ispol'zovanija investicionnyh resursov neftjanoj kompanii [Correlation and regression analysis of the efficiency of investment resources, oil companies] // Vestnik UGNTU. - Vol. 1. №35. - $\mathrm{Pp}$. 15-23.

3. Nizamova G.Z., Gajfullina M.M., Bakulina D.S. Ocenka vlijanija faktorov na jeffektivnost' investicionnoj dejatel'nosti neftjanoj kompanii [Estimation of influence of factors on the efficiency of investment activities of the oil company] // Evrazijskij juridicheskij zhurnal [Eurasian law journal]. — 2018. — №10. Pp. 460-461.

4. Oficial'nyj sajt Islamskogo banka razvitija Islamic Development Bank [Official website of the Islamic Development Bank Islamic De- 
velopment Bank] [Jelektronnyj resurs]. — URL: https://www.isdb.org/isdb-member-countries.

5. Amendola A., Giordano F., Parrella M.L., Restaino $M$. Variable selection in high-dimensional regression: a nonparametric procedure for business failure prediction // Applied Stochastic Models in Business and Industry. - 2017. №33 (4). - Pp. 355-368. - DOI: https://doi. org/10.1002/asmb.2240.

6. Gajfullina M.M., Nizamova G.Z., Musina D.R., Alexandrova O.A. Formation of strategy of effective management of fixed production assets of oil company // Advances in Economics, Business and Management Research. 2017. - Vol. 38. - Pp. 185-190. — DOI: https://doi.org/10.2991/ttiess-17.2017.32.

7. Gayfullina M. M, Nizamova G.Z., Musina D.R., Gareeva Z.A., Tumanova A. U. An integrated approach to assessing the effectiveness of investment projects for the construction of industrial facilities under uncertainty // IOP Conference Series: Earth and Environmental Science,
Vol. 751. International Baikal Investment and Construction Forum «Spatial Restructuring of territories» (4 December 2020, Irkutsk, Russian Federation). - Pp. 1-8. — DOI:10.1088/17551315/751/1/012074.

8. Lee C.F., Chen H. Y., Lee J. Econometric Approach to Financial Analysis, Planning, and Forecasting / In: Financial Econometrics, Mathematics and Statistics. - Springer, New York, NY, 2019. — DOI: https://doi. org/10.1007/978-1-4939-9429-8_5.

9. IsDB Investor Presentation (March 2021) [Электронный ресурс]. - Режим доступа: https://www.isdb.org/pub/generalpublications/2021/isdb-investor-presentationmarch-2021.

10. IsDB Sustainable Investor Presentation (November 2019) [Электронный ресурс]. Режим доступа: https://www.isdb.org/pub/reports/2019/isdb-sustainable-investor-presentation-november-2019.

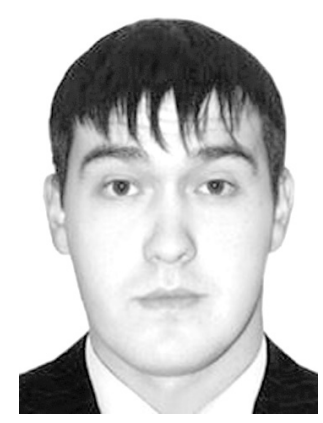

Ишемгулов Ильяс Нилевич - аспирант факультета экономики, финансов и бизнеса Башкирского государственного университета.

Ishemgulov Ilyas Nilevich - Postgraduate Student, Faculty of Economics, Finance and business of Bashkir State University.

450076, г. Уфа, ул. Заки Валиди, 32

32 Zaki Validy str., 450076, Ufa, Russia

E-mail: hannanova_azaliya@bk.ru 